\title{
Benefits of a 3D geological model for major tunnelling works: an example from
} Farringdon, east-central London, UK

D.T. Aldiss ${ }^{1, *}$, M.G. Black ${ }^{2}$, D.C. Entwisle ${ }^{1}$, D.P. Page $^{3}$ \& R.L.Terrington ${ }^{1}$

${ }^{1}$ British Geological Survey, Keyworth, Nottingham, NG12 5GG, UK

${ }^{2}$ Crossrail Limited, 25 Canada Square, Canary Wharf, London, E14 5LQ UK

${ }^{3}$ OtB Engineering UK LLP, 52 Lant Street, London, SE1 1RB, UK

*Corresponding author (e-mail: dta@bgs.ac.uk)

Benefits of a 3D model for tunnelling works

\begin{abstract}
In the design of major construction works, the better the ground conditions are known, the more control there is on the assessment of risks for construction, contract and personnel, and ultimately on final costs. Understanding of the ground conditions is usually expressed as a conceptual ground model that is informed by the results of desk study and of dedicated ground investigation. Using the GSI3D software, a 3D geological model (a model comprised of attributed solid volumes, rather than of surfaces) can be constructed that exactly honours geologists' interpretations of the data. The data is used in its true 3D position.

The 3D model of faulted Lambeth Group (Palaeogene) strata in the area of the proposed new Crossrail Farringdon underground station, in central London, has several types of benefit. These include enabling optimum use of available GI data, including third party data, with confidence. The model provides an understanding of the local geological structure that had not been possible using other commonly-used methods: in particular, it shows the likely distribution of numerous water-bearing coarse deposits and their faulted offsets, which has potentially significant effects on groundwater control. The model can help to target ground investigation, constrain design, and control risk.
\end{abstract}


The design of major construction works requires an understanding of the local ground conditions. In general, the better the ground conditions are known, the more control there is on final costs and schedules and the less uncertainty there is in assessing risk, safety, design and finance. This is especially true for tunnelling works, which may require relatively early commitment to large expenditure on construction equipment, such as tunnel boring machines.

A new underground Farringdon Station (Fig. 1) is proposed in east-central London as part of the Crossrail project. This project is building an east-west rail system linking central London and Canary Wharf with the Channel Tunnel rail link, with Heathrow Airport, and with Berkshire, Essex and North Kent.

The new Farringdon Station is planned to comprise two parallel 300 m-long platform tunnels approximately $11 \mathrm{~m}$ wide and between $15 \mathrm{~m}$ and $37 \mathrm{~m}$ apart, connected by a series of crosspassages. The platform tunnels are to be constructed using mining techniques and lined with sprayed concrete. Inclined escalator shafts will descend between the platform tunnels from ticket halls at each end of the station. Shafts at either end of the station will provide step-free access, ventilation, and space for plant rooms and staff accommodation. The proposed station will be below densely urbanised land currently occupied by an existing railway cutting and by numerous buildings: developments that severely constrain surface access for ground investigation and construction.

\section{Geology of the Farringdon area and its implications}

Since the 1860s an extensive underground rail network has been developed in London. Its construction was considerably eased by the widespread presence of the London Clay Formation to depths of more than $40 \mathrm{~m}$ below ground surface. Typically comprising stiff clay or silty clay, ranging to extremely weak mudstone, this Palaeogene marine deposit is an excellent tunnelling medium. The Farringdon area, however, is at the edge of a structural block that underlies northeast London (Ellison et al. 2004, fig. 45; Ford et al. 2008), within which the base of the London Clay Formation is less than $10 \mathrm{~m}$ below Ordnance Datum, and so less than $30 \mathrm{~m}$ below the ground surface (Fig. 1B). The depth of the planned Crossrail tunnels at Farringdon is constrained by the necessity of passing beneath existing underground infrastructure and beneath late Quaternary alluvial deposits in the floor of the valley of the Fleet River. The tunnels will therefore lie partly within the Lambeth Group and the Thanet Sand Formation, which underlie the London Clay (Fig. 1C; Table 1).

The Lambeth Group, also of Palaeogene age, is between 15 and 20 m thick at Farringdon. As a consequence of its varied fluvial and coastal depositional environments, the Lambeth Group is both vertically and laterally variable in composition (Page \& Skipper 2000; Ellison et al. 2004; 
Table 1). At Farringdon, it mainly comprises red to brown, green or grey multicoloured clays of the 'Mottled Beds' (Upper and Lower Mottled Clay of Ellison et al. 1994; Aldiss 2012), but other lithologies are present, including grey clays, fine silty sands, shell beds, sandy clay and sandy flint gravel. It includes a significant non-sequence, the mid-Lambeth Group Hiatus (Page 1994; Page \& Skipper 2000), beneath which the deposits have been modified by contemporary tropical or sub-tropical weathering and duricrust formation (Table 1).

The lithological variation and, in particular, the presence within the clay of water-saturated sand or gravel beds or lenses present potential difficulties to tunnelling works. These water-bearing layers, if encountered within the excavation and not de-pressurised, could result in a flow of material and face instability, which could in turn result in greater than predicted surface settlement, amongst other potential problems. The consequences for a previous tunnelling project in London are described by Newman (2009). They include local realignment of the planned tunnel and pre-construction ground depressurisation, and the use of compressed air during the intersection of problematic ground.

The Thanet Sand Formation, beneath the Lambeth Group, is between 7 and $11 \mathrm{~m}$ thick at this location. The Thanet Sand Formation is generally a coarsening-up sequence of very dense, finegrained silty sands and silts. Normally in hydraulic continuity with the underlying Chalk Group, the main aquifer, the Thanet Sand Formation often requires dewatering prior to tunnelling work (Linney \& Withers 1998). A depressed main aquifer level at the location of Farringdon Station, however, means that the Thanet Sand Formation will be dry where encountered by the Crossrail works.

At a fairly early stage of ground investigation for Crossrail at Farringdon, it was realised that this geological sequence is further complicated by the presence of faulting. The existence of at least one fault zone crossing the line of the proposed tunnels was recognised but geological correlation between some boreholes nevertheless proved to be problematic. The number, type and orientation of faults remained uncertain. Thus, although Crossrail had undertaken relatively extensive ground investigations (drilling some 30 high quality boreholes in an area about $900 \mathrm{~m}$ long and up to $350 \mathrm{~m}$ wide) and acquired data for a significant number of nearby third party boreholes, by mid-2008 it had not been found possible to establish a sufficiently detailed, coherent ground model for the Farringdon site.

During the planning and development of the scheme design for the station concerns were expressed about the influence of ground conditions on design and construction costs. The presence of water-bearing layers within the Lambeth Group (which apparently varied in distribution and thickness 'at random') was expected to give rise to variable, and locally high, 
pore water pressures, and the fault zone was inferred to be marked by a zone of 'disturbed ground' of unknown width and character.

As a consequence, it was considered necessary to make some very conservative and generalised design assumptions, leading to lengthy discussions regarding the various options to construct the platform tunnels. Extensive de-pressurisation of the sand and gravel units was assumed to be required, using in combination deep wells from the surface and vacuum wells installed from pilot tunnels. The presence of a fault zone of uncertain width and nature could require complex pre-support tunnelling techniques, such as an umbrella arch. A scheme design was created on this basis, even though a sound engineering geological model had still to be developed.

Additional ground investigations were planned for 2009, prior to the commencement of detailed design. The efficient design of a cost-effective ground investigation depends on having some prior understanding of the ground conditions. Coupled with constraints on access, the Crossrail project was faced with the difficulty of designing further ground investigation at Farringdon with little confident knowledge of the structures that required investigation.

The difficulties encountered by experienced project personnel and their consultants in understanding the local geological structure sufficiently to explain the observed variations in sequence and in level between adjacent boreholes can be attributed to the best practice methods then available to create a conceptual ground model.

\section{Development of a conceptual ground model at Farringdon}

The process of developing a ground model generally commences with a desk study of the local geological sequences and proceeds by means of ground investigation (GI) using boreholes and trial pits, commonly complemented by in situ testing and geophysical surveys, as appropriate to local needs and circumstances. Graphic representation is an essential aid to interpretation and to sharing understanding of a particular ground model between all parties involved with the project.

$2 D$ sections

Traditional development of a ground model is assisted by geological correlation between boreholes according to what is known of the local geological sequence, so creating twodimensional (2D) cross-sections. These cross-sections may follow lines of survey (Fig. 2) but for linear routes they are commonly drawn along the proposed lines of construction, that being where the details of the geological model are most needed, although not necessarily where the available data points are situated. Indeed, ground investigation for tunneling works will normally avoid the planned alignments. This is primarily because boreholes may act as a conduit for surface water or groundwater into the tunnel excavation, but there may also be 
aquifer protection issues in allowing ingress of contaminated surface waters. Furthermore, in the case of slurry type TBMs, there may also be problems involved with loss of pressure or loss of slurry itself up an open borehole.

Construction of a cross-section along a linear route in this way can work well if the local geological structure is known, or if the boreholes are very close to the line of section and their spacing is small, relative to local geological variation. In some projects, such as Farringdon, it is not everywhere possible or desireable to drill close to the planned line of construction. Indeed, planned routes may change, possibly as a consequence of GI work, and in any case it is generally advantageous to make use of pre-existing GI data from the general vicinity.

Boreholes that lie off the line of section can be accurately projected on-line, if the local structure is known, by making a vertical adjustment to allow for the apparent dip between the true position of the borehole and its projected position. However, boreholes that have not been projected appropriately are likely to appear to be anomalous. For example, a borehole that has been projected over a horizontal distance of $100 \mathrm{~m}$ by assuming a dip that is incorrect by only $1^{\circ}$ will gain a spurious vertical displacement of at least $1.7 \mathrm{~m}$, which is a significant error in most investigations. A borehole that has been projected across the line of an unrecognised fault is likely to gain an even greater anomalous vertical displacement. Where the local structure is not known with confidence, particularly where it is suspected to be complex, it is safer to project a borehole onto the line of section without making any vertical adjustment (Fig. 2B). Unless the strata are horizontal, or the projection happens to occur along strike and does not cross a fault, this will inevitably introduce an anomaly into the cross-section, but it avoids the risk of creating a larger anomaly by making a false assumption about the structure.

Having projected available borehole data onto the line of cross-section, lines of correlation can then be drawn through the boreholes (Fig. 2B). Difficulties can arise, however, where one or more boreholes do not conform to the lines of correlation indicated by their neighbours. The interpreter must then decide whether the apparently anomalous borehole records are demonstrating some variation in the local geological structure, or have been falsely recorded in some way, or have been projected onto the line of section according to some false assumption about the structure. While it might be thought that increasing the density of data would promote understanding of the local geology, it can be seen from Figure 2B that doing so in areas of complexity can just add to the confusion.

Depending on the interpreter's decision, the interpretation can follow one of several strategies, or perhaps some rules-based or judgement-based combination of them. The interpreter can decide to not honour all individual borehole records, although this runs the risk of disregarding 'good' data, of over-simplifying the interpreted structure and of possibly over-looking some 
significant variation that should be allowed for in the design. An alternative strategy would be to honour all borehole records, regardless of the geological complexity that might thereby be implied, but even where this is possible (in the absence of apparently contradictory evidence) it is likely to create false premises on which to base the design. A further alternative would be to change the elevation of anomalous records to make them conform, preferably so that they are consistent with some re-interpretation of the geological structure, although numerous iterations might be required before a valid solution can be found.

Separating valid data that should be honoured from spurious data that should not requires some assumptions to be made. As discussed below, borehole data validation is most effective and requires least arbitrary assumptions about data quality if a borehole record can be compared with its neighbours in a fully 3D context.

The technique of constructing 2D sections is relatively simple and intuitive, but it is least successful where the geological structure is poorly understood, and this is where a good geological ground model is most necessary. This proved to be the case at Farringdon, where a significant proportion of boreholes projected onto the lines of section close to the tunnel axes did not conform well with a simple geological interpretation (Fig. 2).

\section{Modelled surfaces}

Many of the pitfalls involved in drawing 2D cross-sections can be avoided by first generating individual geological surfaces representing the base (or top) of key geological units. Contours for such surfaces can be drawn manually, but increasingly geological surfaces are generated digitally using one of the many excellent software packages that are available. Indeed, during this work, Paradigm ${ }^{\text {TM }}$ GOCAD® was used for initial appraisal of the data (Fig. 3). A crosssection for a planned linear route can then be drawn from the intersections with the stack of successive surfaces that delimit the local geological units. This method has the advantage that borehole records are left in their true position. It commonly has the disadvantage that the configuration of each surface will depend on the computing algorithms employed, and may not honour all the available data without signification intervention by the operator.

If the local geological sequence comprises a number of layers of uniform thickness and inclination, then the corresponding sets of structure contours on their bounding surfaces will be of uniform spacing and orientation. Deflections of the structure contours away from this simple pattern indicate some variation in unit thickness, or the presence of folding or faulting, or of flaws in the data. The modeller must decide rationally which circumstance is the most likely. Persistence of the same deflections through successive geological surfaces can indicate the position of a fault (or fold axis). The accuracy with which such structures can be located by 
analysing deflections of contour sets will depend on the density of data relative to the amplitude of the structures. Moreover, most geological modelling packages work best if the pattern of faulting is already known, for example from surface mapping or from seismic survey, or if it can be inferred at an early stage in the modelling work-flow. Indeed, modelling algorithms may tend to 'smooth-out' and so disguise perturbations in the modelled surface that indicate that a fault is present.

Many software packages have the further disadvantage that they are sufficiently complex to require a specialist operator to get the best results from their use. The software manipulation required to infer the presence and location of previously unrecognised faults, and to accurately model faulted layers so that they honour the available data, may require a high level of expertise with the software in addition to good geological understanding. Commonly, however, expert knowledge of modelling software and of geology are not found in the same person.

Structure contour maps for individual geological surfaces in the Farringdon area suggest that the regional dip in this area is about $2^{\circ}$ to the south-east, but the many departures from this generality show that some faulting, or perhaps folding, is present (Fig. 3). Unfortunately, the insufficient and irregular data density, together with uncertainties in the reliability or interpretation of some borehole records, make it impossible to resolve well-substantiated structures that explain all of the apparent variation in the data. It is not clear in Figure 3 how many faults are present, nor their orientation or throw. Also, as shown later in this paper, 3D modelling demonstrates that in most of the area the dip is actually about $2^{\circ}$ to the south.

\section{D modelling}

Recognising that the absence of a reliable ground model for Farringdon posed a clear risk to the project, in early 2009 Crossrail commissioned the British Geological Survey to develop a 3D geological model using the GSI3D geological modelling software, before additional ground investigations commenced.

The GSI3D workflow and methodology is described by Kessler et al. (2009). In common with many other modelling packages, GSI3D makes use of borehole records (and can also use interpretations of geophysical information such as seismic sections) to model the subsurface extent of defined geological units. Unlike most (if not all) other modelling packages, GSI3D modelling is based on the manual construction by a geologist of cross-sections that link together borehole records placed in their correct relative positions: this is a process of geological interpretation, not of mathematical interpolation. In other words, GSI3D emulates the process of sketching a cross-section using manual methods, and the operation of the software is sufficiently simple for a geologist to become an expert user fairly rapidly. 
Correlation in the GSI3D cross-sections is generally based on lithostratigraphy, but can also follow lithology, or a combination of characters. An intersecting network of cross-sections is created for each model, precisely embodying the geologist's interpretation of the borehole records in the context of the local geology. The geologist chooses whether to honour each data point, or not. The whole geological sequence can be modelled in each cross-section, maintaining consistent formation thickness. No prior knowledge of the structure is required. If the presence of a fault is inferred, it can be added to the model at any stage in the modelling: indeed, it can be useful to construct an initial 3D model as if no faulting is present, to avoid the model being unduly influenced by preconceived ideas about the local structure.

Only when the cross-sections are complete and mutually consistent is the software used to interpolate surfaces between them. The geologist's interpretation may or may not honour the geological data, but the interpolated surfaces honour the geologist's interpretation. The interpolated surfaces are in turn used by the software to create three-dimensional shapes that together comprise the finished 3D geological model. That model can be viewed as a stand-alone 3D entity that can be dissected, made selectively transparent or otherwise manipulated (Fig. 4); it can be used to generate synthetic cross-sections or borehole prognoses; or it can be used to generate files appropriate to displaying the component geological surfaces or shapes in commonly-used CAD or GIS software packages (Kessler et al. 2009).

\section{Data validation}

Inspection of GI reports and of other kinds of engineering geological documentation suggests that it is not unusual for a civil engineering project to use only ground investigation data commissioned specifically for that project. This is understandable, given that there will usually be greater uncertainty about the work standards, codes of practice, training levels and extent of technical understanding represented by older borehole data. Considering the potential consequences of failure (either structural or contractual), project staff (and their employers) may be reluctant to accept responsibility for data over whose collection they had no control.

However, just because a borehole record is old or appears to be anomalous does not necessarily mean that it is in fact incorrect. Very probably, the record was originally prepared in good faith by competent individuals, and despite being a product of possibly less rigorous working practices, it may be accurate enough to demonstrate the presence of some otherwise unsuspected geological structure. In a large urban project area with complex geology and with an extensive history of development, and where the density of ground investigation data is constrained by logistics, access and cost, it is possible that third party records will provide the confirmation (and perhaps the only indication) that a particular geological structure exists. In this situation it could appear negligent for third party data to be disregarded unless it is clearly erroneous. 
Therefore, where a borehole record is inconsistent with the interpreted geological structure, as shown in a contoured surface or in a cross-section, the modeller must decide if the data is flawed or if it is demonstrating the presence of some additional local geological variation. Some data anomalies can easily be accounted for by re-examination of the original record: perhaps a borehole has been given the wrong position or elevation, or maybe one or more of the borehole intervals was misinterpreted. Where an anomalous record contains no obvious mistake, however, then a familiar dilemma appears: should this record be honoured, or not? The GSI3D modelling methodology provides an integral means of validating individual borehole records, including third party records, and so of resolving this dilemma.

It can be assumed that in a small area bedrock sedimentary formations are continuous, and have uniform thickness and structural attitude, unless proven otherwise. Therefore, if records viewed in their correct 3D context can be seen to be consistent with other records nearby, it can be concluded that they are essentially accurate and representative of the intervening ground. For example, Figure 5 shows a cross-section drawn through eight boreholes in the west of the Farringdon area. Although these were acquired for various purposes at four different times between 1964 and 1992, there is clearly considerable consistency between them. It can be seen that any differences in drilling and sampling practice are sufficiently small for the obviously anomalous intercepts to be identified, and that together they demonstrate a uniform apparent dip of about $2^{\circ}$. This principle can be used to examine subsets of boreholes that lie within individual structural blocks. Individual borehole records that do not conform with the structure indicated by their neighbours can then be recognised as being somehow flawed, with some confidence, and their omission from the model dataset objectively justified.

The Farringdon 3D model was based on existing ground investigation undertaken by Crossrail and on third party borehole records. Validation of the third party records within the 3D modelling process provided an effective means of cheaply increasing the population of borehole records that could be used with confidence from about 35 (drilled for Crossrail) to about 145 . The Farringdon 3D geological model

The 3D geological modelling process was able to delineate each geological unit known to be present (Table 1), including discontinuous sand bodies in the Laminated Beds and the Upper Mottled Clay of the Lambeth Group. Several simple rules were adopted to model these sand bodies: (i) where similar sand occurs in two adjacent boreholes, it is assumed to continue between them; (ii) if it does not, the lateral extent of the sand is inferred to approximate to a radius equal to half the distance to the nearest borehole without sand at the same level; (iii) the maximum thickness proven in boreholes is assumed to be the greatest thickness present; and (iv) 
the sand bodies have curved bases and flat tops. The model made according to these rules includes a sheet-like sand body up to $2 \mathrm{~m}$ thick in the Laminated Beds of the Woolwich Formation and several short channel-like sand bodies (up to $25 \mathrm{~m}$ wide, $3 \mathrm{~m}$ deep and $200 \mathrm{~m}$ long) in the Upper Mottled Clay (Reading Formation) (Fig. 4; Table 1). These geometries conform to what is expected in the respective depositional environments.

The Farringdon model was initially constructed as if no faults were present and with no prior assumptions about the local geological structure. Faults were then introduced where they are required to explain the data anomalies, and where they could be justified by the data. Seven faults were modelled, with downthrows ranging from about $1 \mathrm{~m}$ to about $12 \mathrm{~m}$ (Figs. 4, 6 and 7). Close to the line of the tunnels, the position of most of the faults can be constrained to within an envelope less than $20 \mathrm{~m}$ wide (Fig. 7). None of the faults is shown on current geological survey maps although the existence of the Barbican Fault had been shown by regional 3D geological models of the London area (Ellison et al. 2004, fig. 45; Ford et al. 2008). One, the Smithfield Fault, was known from previous desk studies for Crossrail and the existence of two others had been suspected, although their position and orientation was poorly constrained. The modelled position of the Smithfield Fault has been corroborated by a more recent project borehole.

Most of the fault-blocks individually display a consistent bedding dip of about $2^{\circ}$ to the south (Fig. 6). This contrasts with the impression conveyed by the GOCAD ${ }^{\circledR}$ model of the same dataset, which implies a dip to the south-east (Fig. 3). Some unexplained anomalies do remain and it is likely that there is additional faulting in the north and in the east of the modelled area, although at the time of modelling there was insufficient data to confirm this or to locate any additional faults with confidence.

\section{Benefits of the Farringdon 3D model}

Benefits of the Farringdon geological model arise from the methodology used to make the model, from the better understanding of the ground conditions that it provides, and from the form of the completed model and its outputs.

The GSI3D methodology means that all data are considered in their correct position in 3D space: no projection to a line of section is required. No prior assumptions need be made about the local geological structure. The detailed configuration of each modelled surface is controlled by the modeller, not by modelling algorithms within the software. The modeller is primarily a geologist, not a software expert.

The GSI3D methodology makes it easy to examine individual borehole records in their 3D context of surrounding data and interpretations. The validity of borehole records and their 
interpretations can thereby be assessed objectively, with the benefit that the modeller (and the users) can have greater confidence that the borehole data used are reliable and representative. Also, this method provides a means of objective identification of data that should be excluded. As a consequence, the geological model can be based on a larger population of borehole data, which can be treated with more confidence than otherwise. This provides more detail of the geological sequence and its variations than would be possible with a smaller dataset, and in particular provides better constraint on discontinuous geological units. Furthermore, the larger geographical spread provided by third party data means that the position and orientation of faults within the project area can be determined with greater confidence than if project GI boreholes were used alone. The Farringdon model uses boreholes as much as $300 \mathrm{~m}$ from the planned tunnels, providing excellent constraint on the orientation of faults. Furthermore, because the 3D model shows how each borehole fits into the local geological structure, more reliance can be placed on its logs and associated test data, and their place in the whole conceptual ground model can be better understood. In short, better value can be obtained from GI data that has been acquired by the project, commonly at significant cost.

The Farringdon 3D geological model has provided a degree of geological understanding of the ground that had been found not to be possible using other, commonly-used, methods. The model provides a coherent conceptual ground model of a faulted multi-layered aquifer; it demonstrates with a useful level of accuracy the extent of each identifiable geological unit and of at least seven faults. In particular, it shows the likely distribution of water-bearing sand and gravel deposits and their faulted offsets, which have potentially significant effects on groundwater control. Furthermore, the model allows all parties concerned with the project, from the client and designers through to the contractors on site, to be able to visualise and understand the geological structure and to better appreciate where any risks in construction may exist.

The 3D model can be used to quickly generate synthetic lines of section or synthetic borehole logs, for example to predict ground conditions at a particular point or on an alternative route alignment, to assist the design of on-going ground investigation, for example by assessing the depth to a target horizon or structure.

The optimisation of ground investigations of a particular geological structure depends on knowing what and where that structure is. The less well known, then the greater the chance of drilling more boreholes than are really required, or too few to elucidate the structure (or of drilling boreholes that are either too deep or too shallow), so that either too much money and time is spent, or that full value is not obtained from what is spent because the problem is not resolved. Also, because of the better understanding of geological structure, it arguably confers 
greater flexibility over borehole siting, potentially simplifying the process of gaining access and permission to drill.

On the other hand, the Farringdon 3D model identifies some areas that probably have a more complex structure than can be resolved with current data, and which are, therefore, likely targets for additional investigation.

To complement these processes, the model will indicate how likely it is that test results from nearby boreholes are representative of the intervening ground. It is possible that some physical conditions may vary across faults, so that boreholes on either side of a fault, or within a fault zone, may not be directly comparable for the purposes of such interpolation.

The ability to correctly target ground investigations can quickly compensate for the cost of the 3D geological model, for example by reducing the number of boreholes that need to be drilled, in the more efficient use of rig time, shorter site occupancy and faster delivery of results. Geological modelling using GSI3D is labour intensive, so that detailed local models typically cost between $£ 10^{4}$ and $£ 10^{5}$ to commission, depending on a number of variables such as area, complexity of geology, and data density. By comparison, a modern ground investigation borehole in the Lambeth Group in central London is likely to cost in the order of $£ 10^{3} / \mathrm{m}$ on average, including permissions, mobilisation, sampling, logging and testing. So if the 3D model can help to target and to interpret new ground investigation boreholes, so that, for example, it is found that only two out of a series of six $25 \mathrm{~m}$ boreholes are needed to prove the position of a particular geological structure, then a model costing $£ 10^{5}$ can be said to have paid for itself. The Farringdon 3D model has delivered a significantly better understanding of the geological structure beneath and around the proposed location of a large mined tunnel station. It has also enabled the range in variation of each lithological unit to be defined categorically. The digital outputs from GSI3D can be directly input to computer-aided 3D tunnel design models, enabling the full relationship between the ground and the proposed structure to be established and shown graphically. Where the proposed tunnel intersects the 3D geological model synthetic tunnel face logs can be generated, giving greater confidence in the ground conditions to be met and their likely engineering behaviour. It has also identified gaps in the data set, which targeted ground investigation is planned to resolve.

The outputs from GSI3D, being the best representation of the ground conditions at the site, can be a useful tool in defining the geotechnical baseline for use in for the procurement of construction contracts. It is hoped that during construction the model will be further refined allowing an 'as-built' record to be created. 
This detailed model also has implications for geological investigations into the geology of London, and perhaps further afield. For instance, it shows that faulting with displacements of between $1 \mathrm{~m}$ and $10 \mathrm{~m}$ is likely to be much more widespread than shown by current geological maps and is probably much more common under London than so far suspected.

\section{Conclusions}

Traditional methods of constructing a 2D cross-section for a linear route from nearby boreholes work well where the geology is known, or where it is simple. If the geological structure is not simple, then this method requires a very high data density to be successful.

Geological modelling software designed to calculate geological surfaces to correspond to an array of data points generally works best if there is prior knowledge of the geological structure. Such modelling typically requires a high level of expertise with the software, especially if the geological structure is poorly known, or if it is faulted. Modelling algorithms that 'smooth-out' interpolations between data points can act to disguise the presence of faulting.

The GSI3D geological modelling software is sufficiently simple to be used effectively by a modeller whose primary expertise is in geology. The borehole data are kept in their correct 3D position, so the methodology provides the model maker with the means to validate each borehole log in its local context and to understand the geological structure without prior assumptions. The software honours each data point, unless the geologist specifically chooses that it should not. The GSI3D methodology enables more third party data to be used with confidence, and for a 3D geological model generated by GSI3D to make best use of what data there is. For these reasons, it was found that a GSI3D 3D geological model could provide a detailed ground model of a faulted multi-layer aquifer in central London that is consistent with available ground investigation data, where other methodologies could not.

The model user thereby has a tool to help target ground investigation, to constrain construction design and to control risk. Short-term financial savings, for example in ground investigation, are comparable with the cost of the commissioned model; potential savings over the life of the project, for example in the understanding of risk, design and construction, are considerably greater.

\section{Acknowledgements.}

DTA, DCE and RLT publish with the approval of the Executive Director, BGS.

\section{References}

ALDISS, D T. 2012. The stratigraphical framework for the Palaeogene successions of the London Basin, UK. British Geological Survey Open Report OR/12/004. 
Ellison, R A, KNOX, R W O, Jolley, D W, \& KING, C. 1994. A revision of the lithostratigraphical classification of the early Palaeogene strata of the London Basin and East Anglia. Proceedings of the Geologists' Association, 105, 187-197.

Ellison, R A, Woods, M A, Allen, D J, Forster, A, Pharaoh, T C, \& King, C. 2004. Geology of London. Memoir of the British Geological Survey, Sheets 256 (North London), 257 (Romford), 270 (South London) and 271 (Dartford) (England and Wales).

Ford, J R, Burke, H F, Royse, K R, \& MATHERs, S J. 2008. The 3D geology of London and the Thames Gateway: a modern approach to geological surveying and its relevance in the urban environment. Cities and their underground environment : 11th European e-conference of International Association for Engineering Geology, September 2008, Madrid, Spain, 15-19.

Kessler, H, MAthers, S, \& SOBISCH, H-G. 2009. The capture and dissemination of integrated 3D geospatial knowledge at the British Geological Survey using GSI3D software and methodology. Computers \& Geosciences, 35, 1311-1321.

LinNeY, L F, \& WiThERS, A D. 1998. Dewatering the Thanet Beds in SE London: three case histories. Quarterly Journal of Engineering Geology and Hydrogeology, 31, 115-122.

NEWMAN, T. 2009. The impact of adverse geological conditions on the design and construction of the Thames Water Ring Main in Greater London, UK. Quarterly Journal of Engineering Geology and Hydrogeology, 42, 5-20.

PAGE, D P. 1994. The engineering geology of the Lambeth Group (Woolwich and Reading Beds), London. MSc thesis, University of Surrey.

PAGE, D P, \& SKIPPER, J A E. 2000. Lithological characteristics of the Lambeth Group. Ground Engineering, 33, 38-43. 
Table 1. Geological sequence in the Farringdon area.

\begin{tabular}{|c|c|c|c|}
\hline \multicolumn{2}{|c|}{ Geological unit } & Typical composition & Local thickness \\
\hline \multicolumn{2}{|c|}{ Made ground } & $\begin{array}{l}\text { Anthropogenic deposits, highly } \\
\text { variable }\end{array}$ & $\begin{array}{l}\text { Mostly between } 1 \text { and } 4 \mathrm{~m} \text {, } \\
\text { locally more than } 12 \mathrm{~m}\end{array}$ \\
\hline \multicolumn{2}{|c|}{ Alluvium } & $\begin{array}{l}\text { Soft to firm clay/silt or sandy } \\
\text { clay/silt or silty/clay sand, } \\
\text { overlying gravel }\end{array}$ & $\begin{array}{l}\text { Mostly less than } 2.5 \mathrm{~m} \text { but } \\
\text { locally more than } 5.5 \mathrm{~m}\end{array}$ \\
\hline \multicolumn{2}{|c|}{$\begin{array}{l}\text { Hackney Gravel } \\
\text { Member }\end{array}$} & $\begin{array}{l}\text { Loose to very dense sand and } \\
\text { gravel in varying proportions }\end{array}$ & $\begin{array}{l}\text { Generally between } 1 \text { and } 4 \mathrm{~m} \\
\text { but locally more than } 5 \mathrm{~m}\end{array}$ \\
\hline \multicolumn{2}{|c|}{ London Clay Formation } & $\begin{array}{l}\text { Firm to very stiff or hard clay or } \\
\text { silty clay, with some silt and } \\
\text { sandy clay }\end{array}$ & $\begin{array}{l}\text { Less than } 3 \mathrm{~m} \text { to more than } \\
38 \mathrm{~m}\end{array}$ \\
\hline \multirow{8}{*}{ 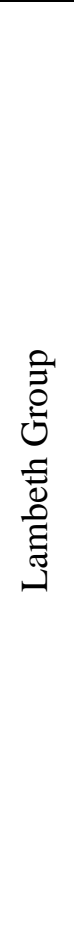 } & \multirow{2}{*}{$\begin{array}{l}\text { Upper Mottled } \\
\text { Clay }\end{array}$} & \multirow{2}{*}{$\begin{array}{l}\text { Stiff to hard clay and silt, with } \\
\text { some sand and occasional gravel. } \\
\text { Dense to very fine- to medium- } \\
\text { grained sand in channels }\end{array}$} & Between 4 and $8 \mathrm{~m}$ \\
\hline & & & 0 to $3 \mathrm{~m}$ \\
\hline & \multirow{2}{*}{ Laminated Beds } & \multirow{2}{*}{$\begin{array}{l}\text { Firm to very stiff laminated silts } \\
\text { and clays; some sand. } \\
\text { Dense to very dense laminated } \\
\text { fine- to medium-grained sand in } \\
\text { sheets }\end{array}$} & 0 to $2 \mathrm{~m}$ \\
\hline & & & 0 to $2 \mathrm{~m}$ \\
\hline & $\begin{array}{l}\text { Lower Shelly } \\
\text { Beds }\end{array}$ & $\begin{array}{l}\text { Stiff to hard organic often shelly } \\
\text { clay with shells }\end{array}$ & \\
\hline & $\begin{array}{l}\text { Lower Mottled } \\
\text { Clay }\end{array}$ & $\begin{array}{l}\text { Very stiff to hard clay, or sandy } \\
\text { clay and fine to medium sands }\end{array}$ & Mostly between 2 and $5 \mathrm{~m}$ \\
\hline & $\begin{array}{l}\text { Upnor Formation } \\
\text { 'Pebble Beds' }\end{array}$ & $\begin{array}{l}\text { Dense to very dense flint gravel } \\
\text { or cobbles in fine to medium } \\
\text { sand, sandy clay or clayey sand }\end{array}$ & Mostly between 1 and $3.5 \mathrm{~m}$ \\
\hline & Upnor Formation & $\begin{array}{l}\text { Dense to very dense fine to } \\
\text { coarse-grained sand, with flint } \\
\text { gravel and shells varying to firm } \\
\text { to very stiff laminated clay or } \\
\text { sandy clay }\end{array}$ & Between 1.5 and $4.5 \mathrm{~m}$ \\
\hline \multicolumn{2}{|c|}{ Thanet Sand Formation } & $\begin{array}{l}\text { Very dense silty fine-grained } \\
\text { sands, grading down to stiff to } \\
\text { hard silty clay with flint gravel }\end{array}$ & Mostly between 7 and $11 \mathrm{~m}$ \\
\hline \multicolumn{2}{|c|}{ Chalk Group } & Chalk with flint nodules & More than $180 \mathrm{~m}$ \\
\hline
\end{tabular}

Bold line marks the base of Quaternary superficial deposits, at 'geological rockhead'.

All the bedrock is of Palaeogene age, except for the Chalk, which is of Upper Cretaceous age. Dashed line marks the mid-Lambeth Group Hiatus (Page, 1994; Page and Skipper, 2000). 

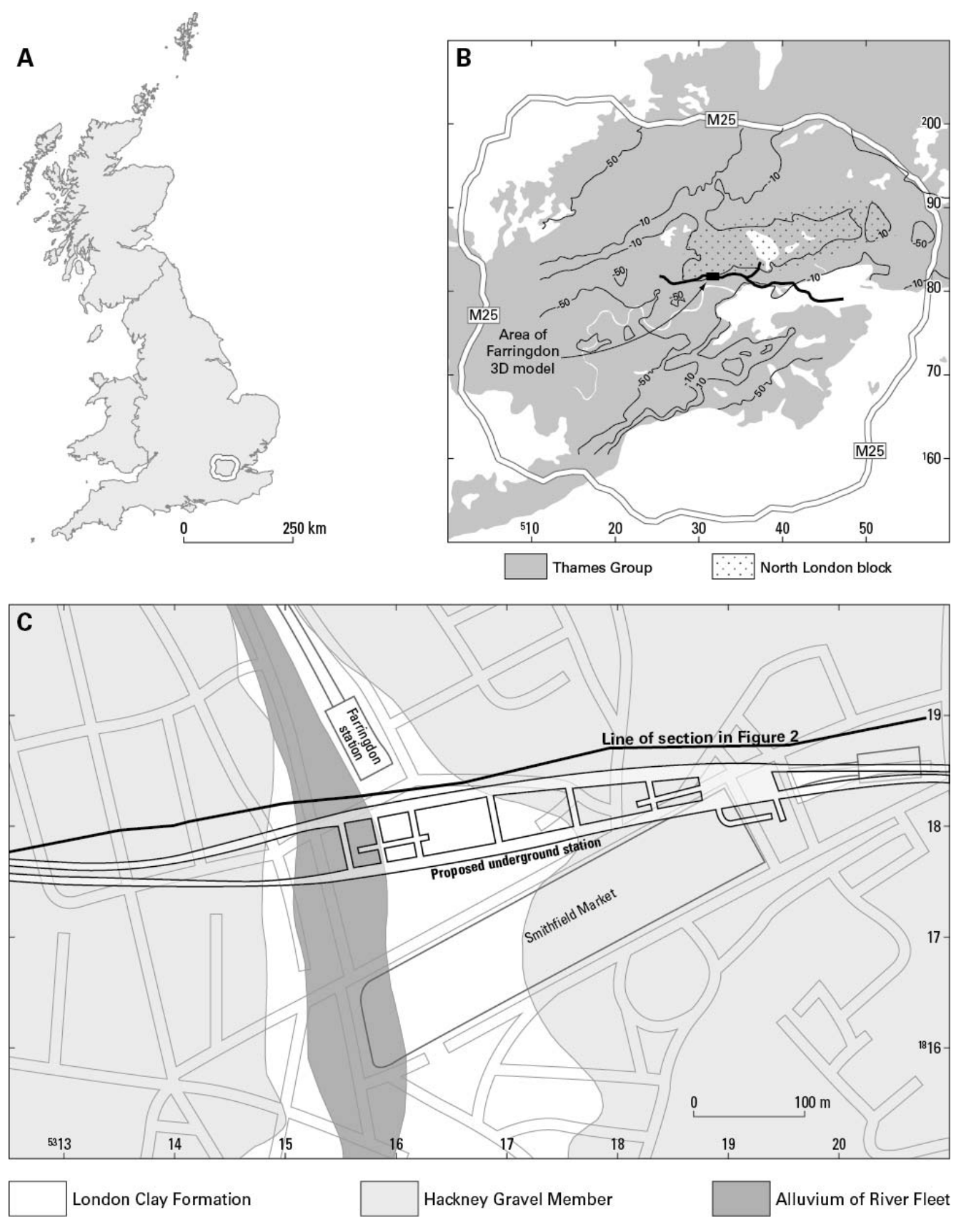

Contains Ordnance Survey data @Crown Copyright and Database rights 2012. Licence No. 100021290

Figure 1: Location of Farringdon 3D geological model

A, B: Outline position of London indicated by the M25 orbital motorway.

B: Contours mark the base of the London Clay (Thames Group) in metres relative to Ordnance Datum. Thick line marks the underground extent of the proposed Crossrail railway.

C: Area of geological model. The outline position of the proposed Crossrail Farringdon station and running tunnels is approximate and the design is indicative. 


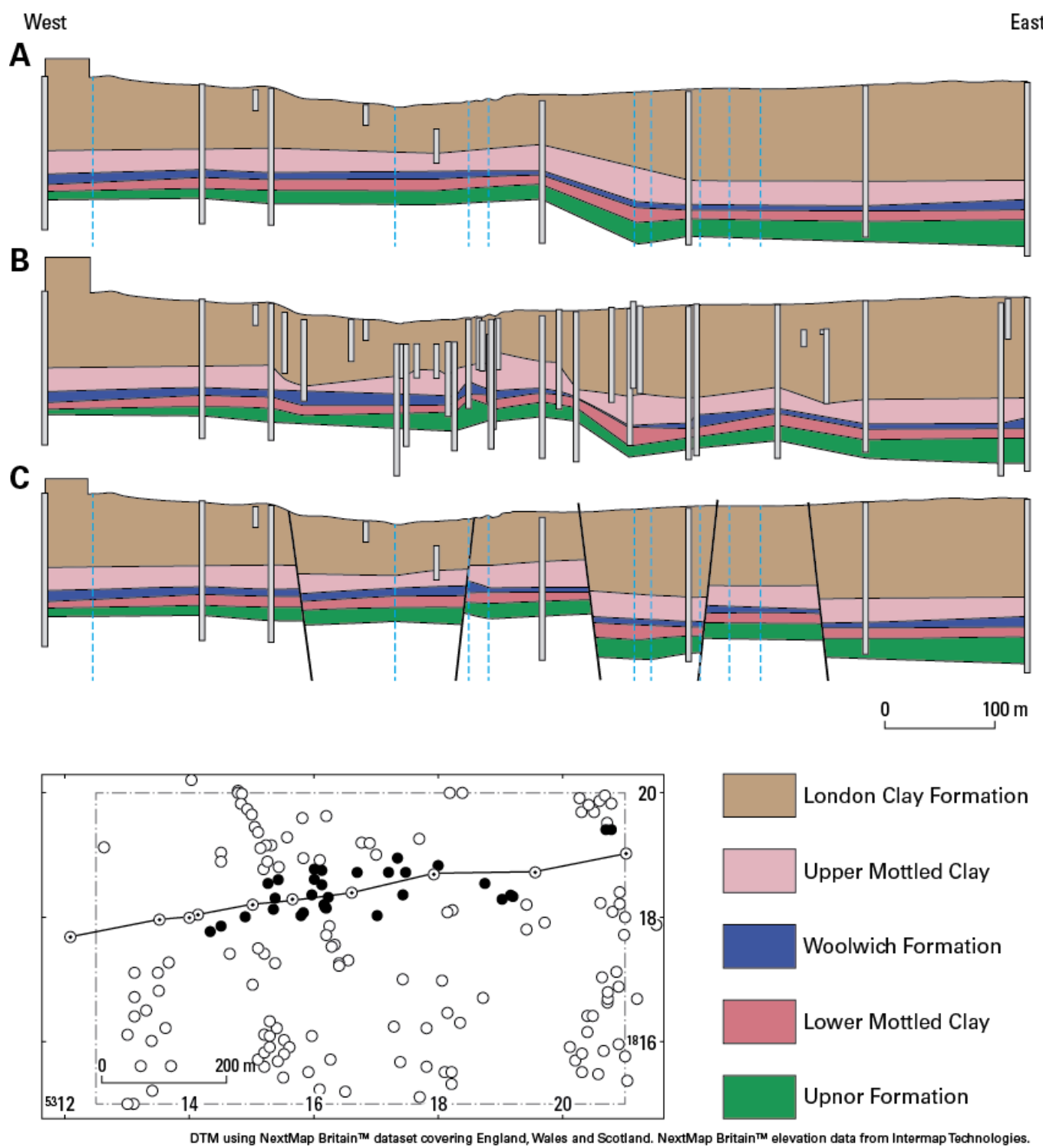

\section{Figure 2: Simplified cross-section of the Farringdon station area}

The borehole interpretations are those that have been validated by the 3D modelling process.

A: Line of section between boreholes marked with point and circle in inset plan. From GSI3D model constructed without faults and partly constrained by intersecting cross-sections (vertical dashed lines). There are too few data in this section alone to infer the full extent of faulting.

B: Same line of section as A, with all boreholes within $50 \mathrm{~m}$ (closed circle on inset plan) projected horizontally onto the line of section. This section emulates the construction of a 2D cross-section outwith GSI3D. Some faulted offsets are fairly clear but others remain ambiguous.

C: As A, but from GSI3D model constructed with faults, and partly constrained by intersecting crosssections (vertical dashed lines). The position of most of these faults can be picked out in Section B, but in some cases their interpretation would be speculative and their position is mostly poorly constrained (compare Figure 7) 


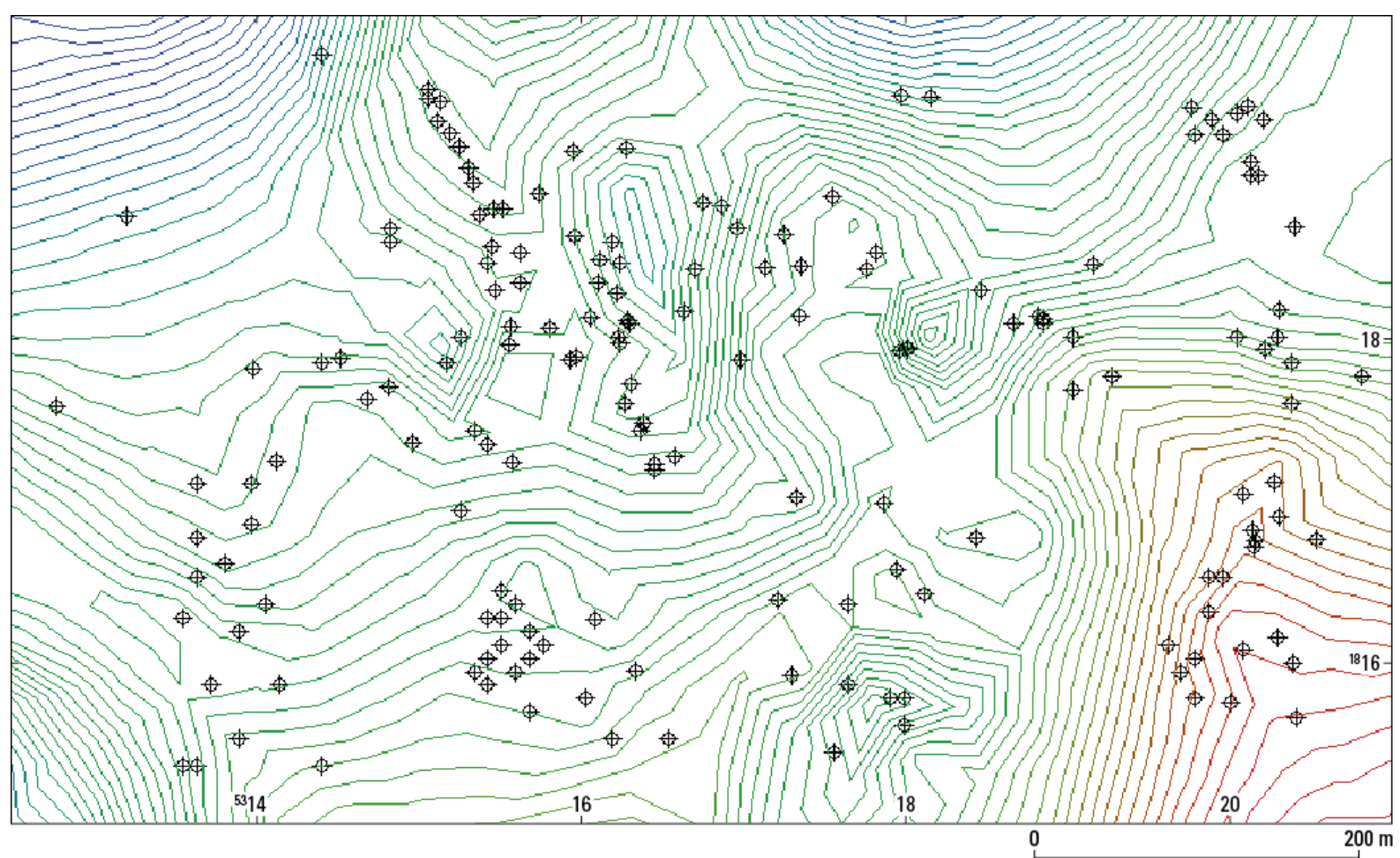

Figure 3: GOCAD ${ }^{\circledR}$ surface for the elevation of the base of the London Clay Formation

Contour interval is $1 \mathrm{~m}$ relative to Ordnance Datum, level decreasing from north to south-east. Symbols indicate borehole location. Compare with Figure 6 . Note that this analysis used only borehole interpretations that have been validated by the 3D modelling process. 


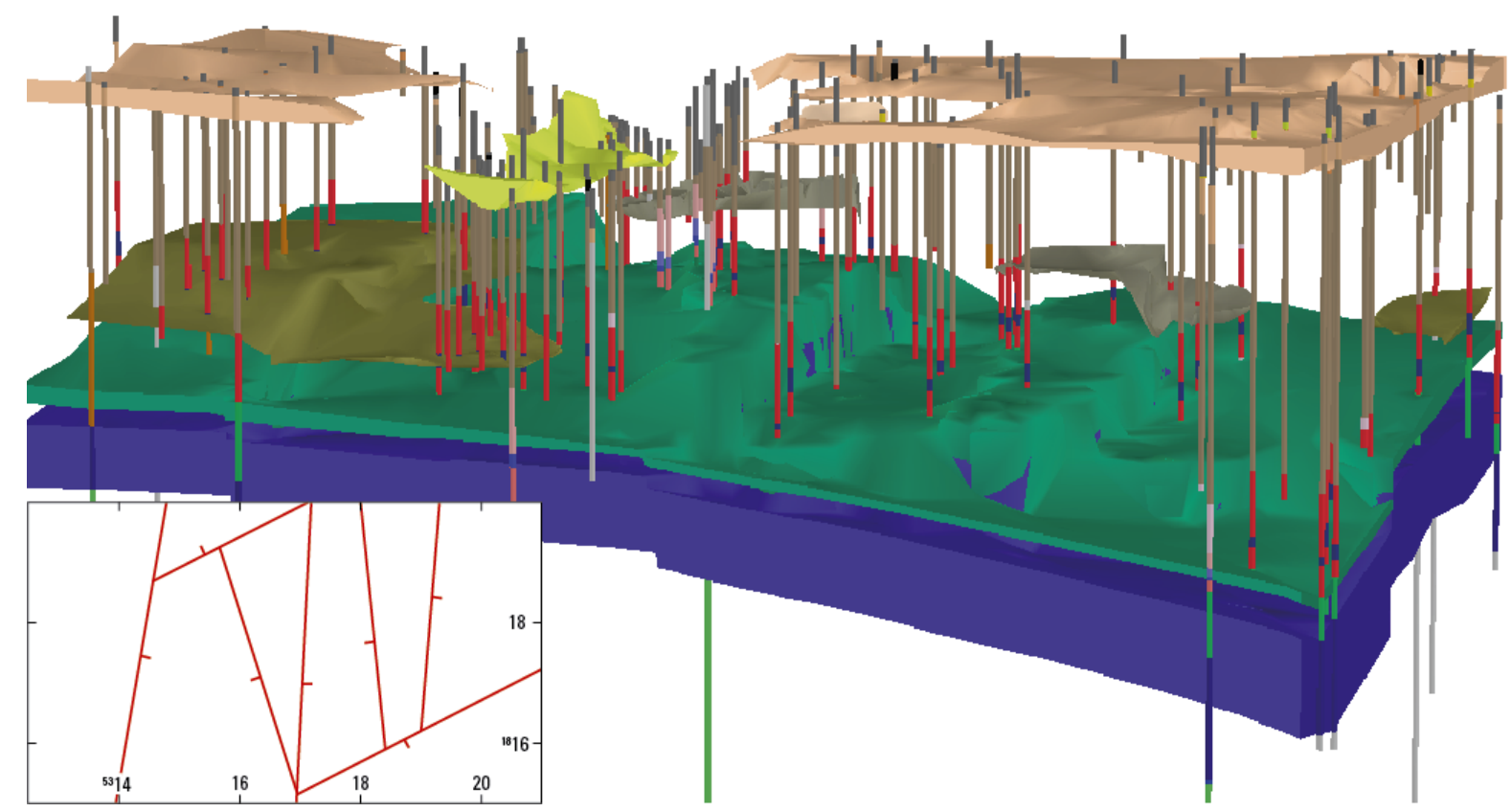

Figure 4: Sand and gravel (water-bearing) units in the Farringdon GSI3D 3D geological model, with borehole 'sticks'

Units composed mainly of silt or clay, and the Chalk Group, (Table 1) have been omitted for clarity.

Inset is a plan of the faults in this model, with direction of downthrow indicated (compare Figures 6 and 7).

Area is $850 \mathrm{~m} \times 500 \mathrm{~m}$; thickness about $80 \mathrm{~m}$, viewed from the south-east. From top: Hackney Gravel Member: pale brown; alluvium: yellow; Sand in Upper Mottled Clay: mid-grey; Sand in Laminated Beds: olive green; Upnor Pebble Beds: grass green; Thanet Sand: blue. See Table 1 for details. The bedrock units are faulted; the Thanet Sand is patchily visible beneath the Upnor Pebble Beds in the planes of faulting. 


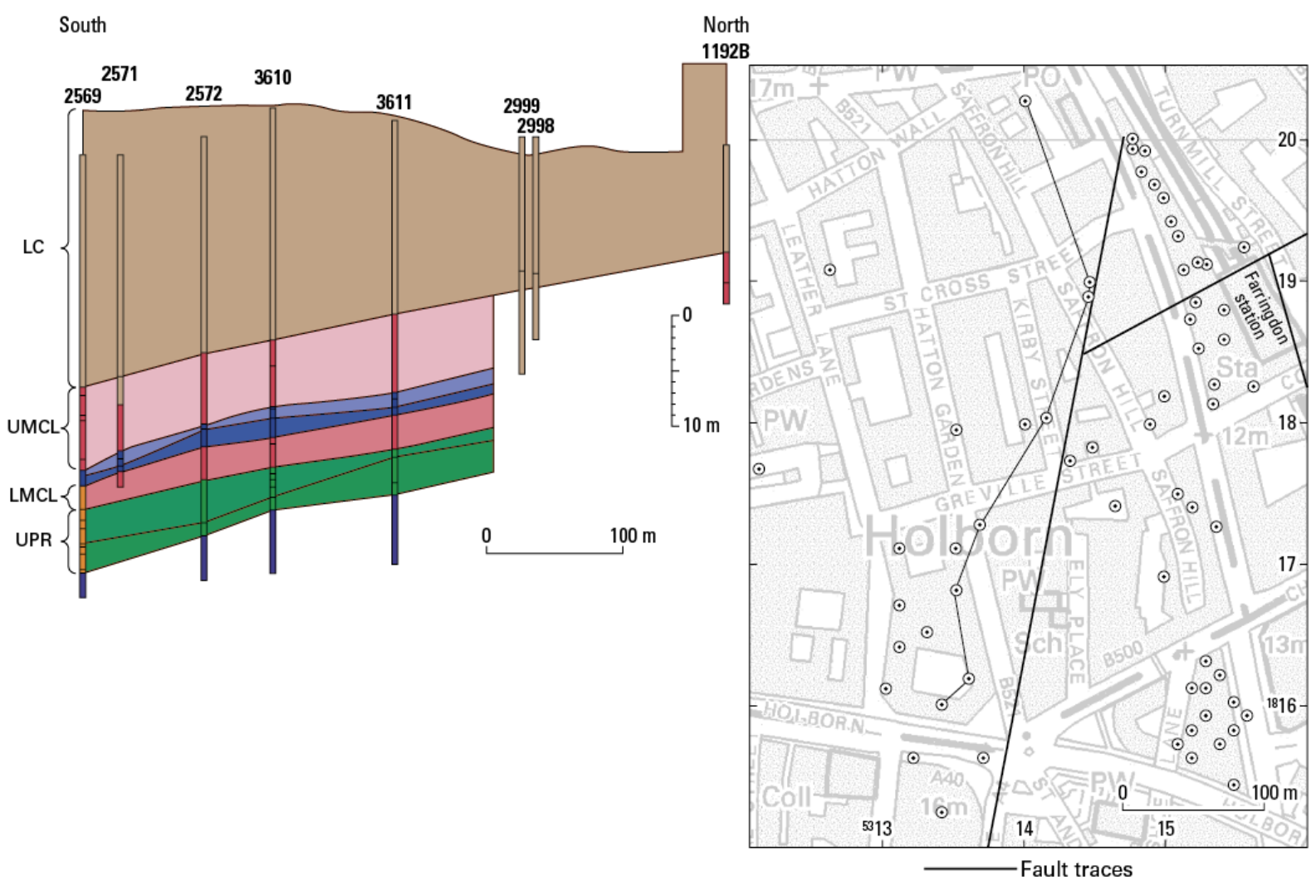

Contains Ordnance Survey data @Crown Copyright and Database rights 2012. Licence No. 100021290 DTM using NextMap Britain ${ }^{T M}$ dataset covering England, Wales and Scotland. NextMap Britain ${ }^{T M}$ elevation data from Intermap Technologies.

\section{Figure 5: GSI3D cross-section in west of Farringdon area}

GSI3D cross-section in west of Farringdon area. Symbols for bedrock formations as in Table 1. Eight boreholes of disparate provenance and age (from 1964 to 1992) show good agreement, except that 2998 and 2999 have been given an imprecise start height. Anomalies in the classification of UMCL as LC are apparent in three boreholes. Index numbers are those of the BGS Single Onshore Borehole Index, in which they are prefixed by TQ38SW. Borehole logs can be inspected on-line via http://www.bgs.ac.uk/data/boreholescans/home.html or by application to enquiries@bgs.ac.uk. 


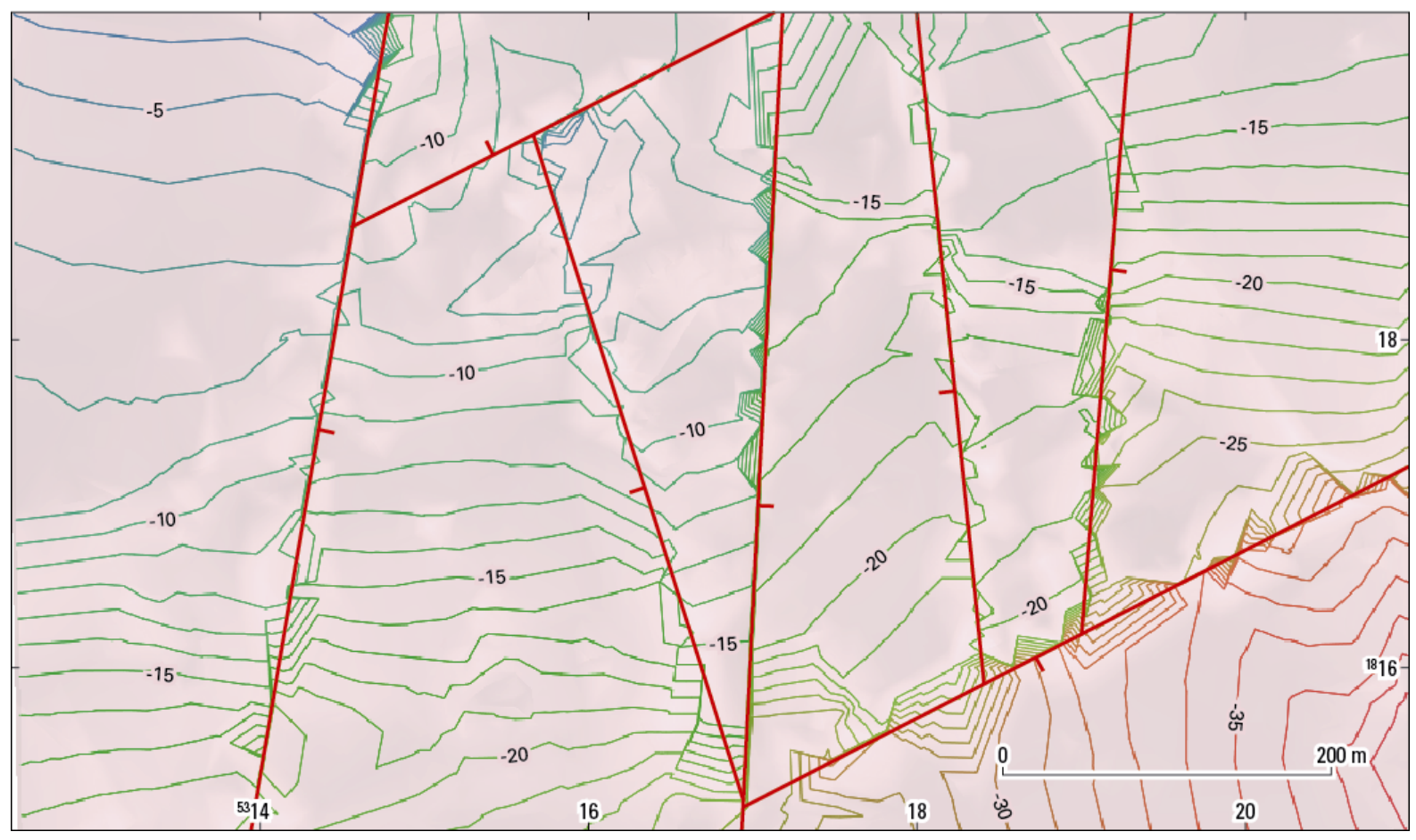

Figure 6: GSI3D-modelled structure contours on base of Upper Mottled Beds

Contour interval is $1 \mathrm{~m}$; range from $-4 \mathrm{~m}$ Ordnance Datum (OD) in north-west corner to $-38 \mathrm{~m}$ OD in south-east. Faults in red with direction of downthrow shown by ticks. Modelling artefacts close to the fault planes should be disregarded. In most of the area, the dip is about $2^{\circ}$ to the south; in the south-east corner, which is south of the North London structural block (Figure 1), the dip is to the east. 


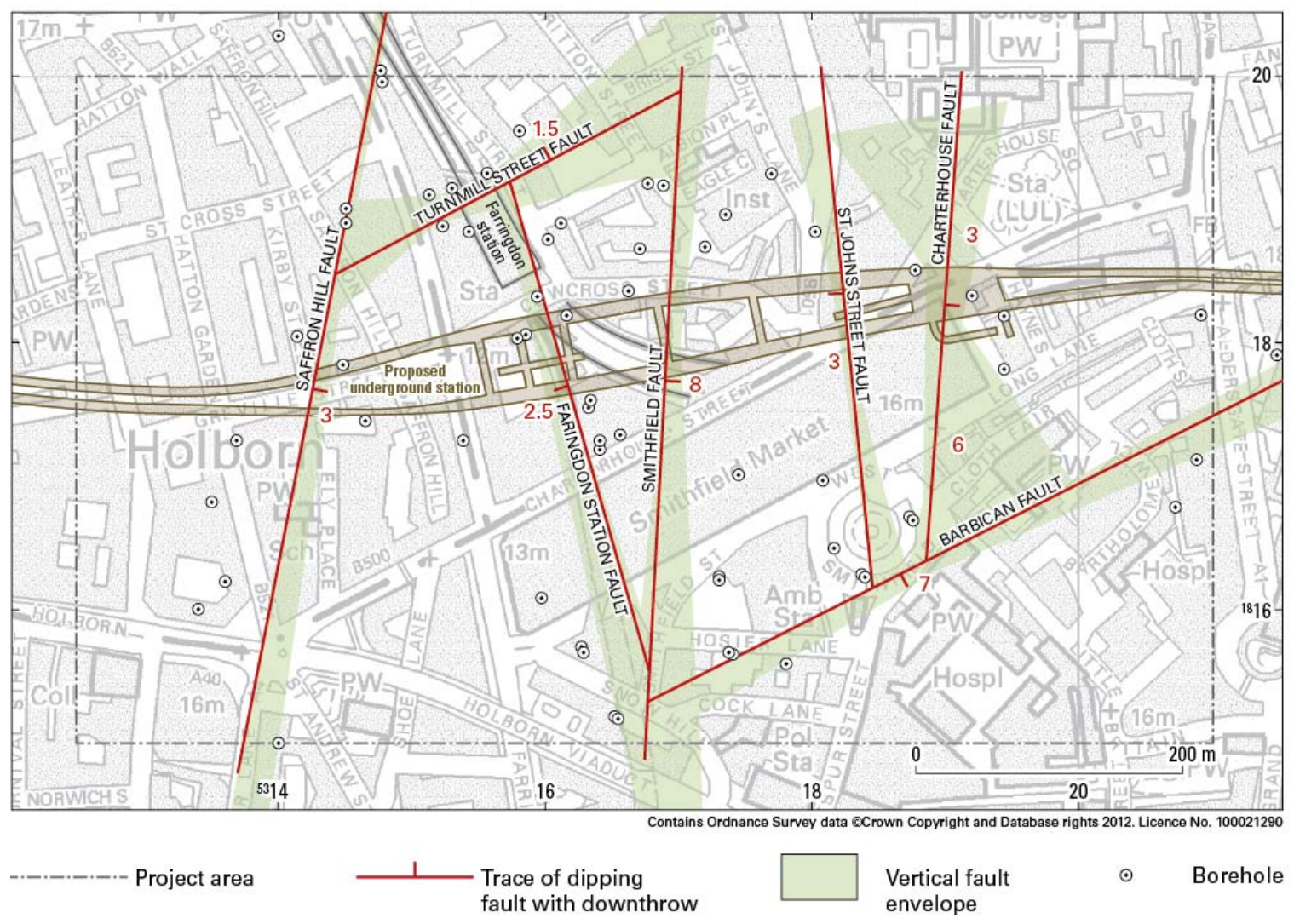

Figure 7: Fault envelopes

The fault envelopes each indicate the range of possible positions for a vertical fault that would account for the offsets observed in the GSI3D model, as constrained by boreholes within their respective footwall and hanging wall blocks. However, the faults marked have been modelled as normal faults dipping at $70^{\circ}$ and these are more closely constrained by the borehole data than indicated by the envelopes for vertical faults. The outline position of the proposed Crossrail Farringdon station and running tunnels is approximate and the design is indicative. 